\title{
NO CAÇAR DOS ERROS, A LÍNGUA QUE ESCAPA ${ }^{1 *}$
}

\author{
DEBBIE NOBLE ${ }^{* *}$
}

\begin{abstract}
RESUMO: Este artigo, ancorado na Análise do Discurso pêcheuxtiana, objetiva analisar o funcionamento dos dizeres sobre o revisor de textos da publicidade a partir de um corpus experimental, que consta de entrevistas com sujeitos envolvidos na etapa de revisão do processo de criação publicitária. Podemos dizer que o objeto analisado é bastante específico, e, até mesmo, contraditório, posto que a publicidade, em geral, trabalha com uma linguagem coloquial, enquanto a revisão de textos pode ser vista como uma tentativa de blindar a língua, torná-la perfeita e evitar os erros. No entanto, ao observar esta contradição, percebemos algumas outras possibilidades de pensar a língua e o espaço de dizeres da publicidade. A relação língua/revisão de textos permeia as sequências discursivas (SDs) analisadas. Nelas, observamos uma relação de repetibilidade na forma de pré-construídos: o revisor de textos é descrito como um sujeito que domina plenamente a língua portuguesa, um detentor dos conhecimentos gramaticais, uma vez que se toma a noção de língua pela de gramática. Assim, buscamos compreender de que forma esses pré-construídos se constituíram historicamente e que regiões do interdiscurso são mobilizadas para que intervenham como efeito de memória nos dizeres desses sujeitos.
\end{abstract}

Palavras-chave: língua; revisão de textos publicitários; análise do discurso.

ABSTRACT: This paper, based on the theory of Discourse Analysis proposed by Michel Pêcheux, aims to analyze the way the discourses about the text reviewer function in the discursive space of advertising, considering an experimental corpus, which consists of interviews with subjects involved in the reviewing phase of the advertising creative process. It is possible to say that the analyzed object is quite specific and even contradictory, considering that, in general, advertising works with colloquial language while text reviewing can be seen as an attempt to armor the language, making it perfect and free from mistakes. However, when we observe this contradiction, we notice some other possibilities to think the language and the discursive space here analyzed. The relation language/text revision permeates the discursive sequences, where we observe a relation of repeatability in a pre-constructed form: the text reviewer is described as a subject who completely dominates the Portuguese language, the bearer of grammatical knowledge, since the language is taken by its grammatical aspect. Thus, we aim at comprehending how these pre-constructed elements were historically constituted and which regions of the interdiscourse are mobilized in order to intervene as memory effect in the saying of these subjects.

Keywords: language; advertising text revision; discourse analysis.

${ }^{1} \mathrm{O}$ presente artigo é derivado da pesquisa de mestrado da autora, intitulada "Quem mexeu no meu texto: língua, poder e autoria nos dizeres sobre o revisor de textos da publicidade", desenvolvida na UFRGS sob orientação da Profa. Dra. Solange Mittmann, e contou com o apoio financeiro da CAPES e da Fapergs no período de 2014 a 2016.

*Universidade do Sul de Santa Catarina (Unisul), Florianópolis SC, Brasil. debbiemnoble@, gmail.com 


\title{
1 INTRODUÇÃO
}

\begin{abstract}
"O revisor tem este notável talento de desdobrar-se, desenha um deleatur ou introduz uma vírgula indiscutivel, e ao mesmo tempo, aceite-se o neologismo, heteronimiza-se, é capaz de seguir o caminho sugerido por uma imagem, uma comparação, uma metáfora...” (SARAMAGO, 1989, p. 19).
\end{abstract}

Qual o lugar do revisor de textos na publicidade? Como ele e seu trabalho são discursivizados na publicidade? Como se pensa a língua a partir desse "espaço de dizeres" que é a publicidade? Partindo dessas questões, o presente trabalho tem por objetivo pensar no lugar do revisor de textos da publicidade pela lente da Análise do Discurso de linha francesa.

Sabemos que, em um primeiro olhar, o revisor de textos procura os desvios mais aparentes: as letras que faltam em uma palavra, os acentos fora de lugar, um espaço ou ponto a mais ou a menos. O revisor trabalha, muitas vezes, com a ilusão da perfeição, da completude, com a ilusão de que é possível preencher as faltas, acertar os lugares, aparar as arestas. O publicitário, por sua vez, trabalha com a criatividade, com a ilusão da originalidade, de que seu texto é fluido e que serve a comunicar a partir de grandes "sacadas". Já o analista do discurso trabalha na direção contrária: toma a incompletude como constitutiva do discurso, entende que a língua falha, que os sentidos deslizam, que sempre poderiam ser outros (mas não qualquer um), que os lugares - sociais, discursivos - estão à deriva.

Diante disso, este trabalho visa compreender o lugar ocupado pelo revisor de textos no que denominamos "espaço de dizeres da publicidade", por meio da análise de dizeres sobre o sujeito revisor da publicidade. Para os objetivos deste artigo, tomamos alguns desses dizeres como exemplares, constituindo um corpus experimental, composto por entrevistas realizadas em três agências de publicidade da cidade de Porto Alegre/RS.

As agências foram eleitas pelo critério de maior aceitação à realização da pesquisa, devendo possuir pelo menos um revisor de textos formado em Letras. Duas das agências trabalhavam prioritariamente com propaganda offline, possuindo também um núcleo específico para peças digitais. Somente uma das agências possuía foco em publicidade on-line, no entanto, as diferenças da revisão on-line e off-line não foram aqui abordadas, uma vez que os entrevistados possuíam mais tempo de trabalho com off-line e os aspectos relativos à revisão on-line foram pouco aprofundados.

Para selecionar os entrevistados, estabelecemos o critério de escolha de profissionais que, segundo nosso conhecimento prévio sobre agências de

${ }^{2}$ Podemos definir "espaço de dizeres" como uma ambiência, um espaço comum, sem endereço fixo ou físico, em que determinados tipos de discursos são produzidos por sujeitos que se inscrevem em certos lugares discursivos e, posteriormente, ocuparão determinadas posições-sujeito e cujos discursos são determinados por se realizarem nesse espaço. 
publicidade, envolvem-se diretamente na etapa de revisão de anúncios. Assim, conversamos com três redatores, dois atendimentos publicitários, três revisores $\mathrm{e}$ um chefe de estúdio.

As entrevistas foram realizadas individual e presencialmente, de forma oral, no período de março a abril de 2014, sendo gravadas e, posteriormente, transcritas, compondo, assim, o que Aiub (2012) denomina arquivo constituído, ou seja, um arquivo que abarcaria os materiais de coleta do analista e que dariam origem, após o trabalho de leitura e análise, aos corpora experimentais, ou seja, aqueles "que equivalem à produção de sequências discursivas por locutores colocados em uma situação experimental definida" (COURTINE, 2009, p. 77).

Em um primeiro olhar para o corpus, uma repetibilidade já foi observada: o revisor de textos aparece nesses dizeres como um corretor de erros, ou seja, quando se fala em revisão de textos, fala-se em correção de erros. Essa repetibilidade, segundo nossas hipóteses, pode estar ligada a uma concepção de língua que a relaciona à gramática normativa, ancorada em uma memória social que envolve a língua materna (o português brasileiro) funcionando como uma língua estrangeira: aquela da qual não é fácil apropriar-se, sendo preciso estudo e conhecimento das normas que a regem. Assim, o sujeito acredita não ter domínio de sua língua materna, confundindo o saber gramatical com a própria língua.

Tendo isso em vista, propomos, neste artigo, uma discussão sobre essa memória social da língua, bem como a relação desta com o acesso, por meio da memória discursiva, a um arquivo de saberes sobre o revisor de textos da publicidade. Além disso, nos propomos a compreender de que ordem é a língua da criação publicitária.

\section{SOBRE A MEMÓRIA DISCURSIVA E O FUNCIONAMENTO DOS PRÉ-CONSTRUÍDOS}

Nosso corpus de análise está permeado pela relação língua/revisão de textos. Um primeiro olhar para nosso corpus já revela uma repetibilidade colocada como evidente: o revisor de textos é descrito como um sujeito que domina plenamente a língua portuguesa, além de ser discursivizado como um detentor dos conhecimentos gramaticais. Isso ocorre, provavelmente, por uma relação parafrástica ao se tomar a noção de língua pela de gramática, isto é: ao se falar de língua, fala-se em gramática.

Para compreender, então, de que forma esses dizeres se constituem historicamente, selecionamos algumas sequências discursivas que podem ser consideradas exemplares da repetibilidade mencionada. Com esta análise, pretendemos compreender que regiões do interdiscurso estão sendo mobilizadas, fazendo com que intervenha esse pré-construído como efeito de memória no dizer desses sujeitos sobre a língua. Para isso, necessário se faz distinguirmos as noções de memória e de pré-construído para, posteriormente, observar como funcionam nos dizeres sobre o revisor. 
Assim como a concepção de sujeito com que trabalhamos em AD não é a de um sujeito empírico, essa memória não é cognitiva, nem individual: trata-se de uma memória discursiva, que, segundo Orlandi (2010a), está ligada à existência histórica do enunciado, como um saber discursivo que constituiria todo dizer, ou seja, algo que já estaria falando antes de qualquer outro dizer.

Pêcheux (1999, p. 52) propõe a noção de memória discursiva relacionando-a aos pré-construídos, quando afirma que a memória é o que "vem restabelecer os 'implícitos' (quer dizer, mais tecnicamente, os pré-construídos, elementos citados e relatados, discursos transversos, etc.) de que sua leitura necessita”.

Na mesma perspectiva, para Leandro Ferreira (2012), a memória situa-se na ordem do enunciável. Assim, os pré-construídos são recortados do interdiscurso pela memória, que os mobiliza no nível do intradiscurso. Podemos afirmar ainda que a memória está ligada ao já-dito, sendo um recorte do todo do interdiscurso. Desse todo, alguns sentidos são ativados dentro de cada FD. Logo, "se a memória discursiva recorta os sentidos e os atualiza no acontecimento da linguagem, ela o faz determinada pelo interdiscurso, o lugar de todos os dizeres" (LEANDRO FERREIRA, 2012, p. 145).

O pré-construído, segundo Pêcheux, é uma noção proposta por Paul Henry, designando o que é anterior e exterior ao discurso. Para Pêcheux (2009 [1975]), o pré-construído é apresentado como o "sempre-já-aí" da interpelação ideológica, que impõe-fornece a realidade e seu sentido sob a forma de universalidade.

No entender de Hansen (2010, p. 04), o pré-construído é “um elemento do interdiscurso re-inscrito no (intra)discurso do sujeito e caracteriza-se, pois, por ser proveniente da exterioridade, proveniência esta que é esquecida".

Nesse sentido, acreditamos que a concepção de língua que aparece nas Sequências Discursivas (doravante SDs) aqui analisadas é decorrente de uma memória de língua que funciona, nos dizeres sobre o revisor de textos, como um pré-construído. Por este motivo, observaremos, a seguir, a construção histórica dessa memória, para, posteriormente, ver como funcionam os pré-construídos em nossas análises.

\subsection{Da construção da língua nacional à gramatização}

Pensando na construção histórica de uma memória sobre a língua portuguesa no Brasil, observamos de que forma a colonização contribuiu para um ideal de língua nacional que passa pela busca do estabelecimento de padrões normativos do Português brasileiro. Assim, observamos o funcionamento dos enunciados na história, retomando uma memória, já que são os sentidos dela derivados, "os responsáveis por fazerem surgir (ou não) em uma memória social aquilo que é próprio de um determinado processo histórico" (LEANDRO FERREIRA, 2012, p. 144), isso porque da memória resulta uma relação da linguagem com a história. A memória histórica tem como função, portanto, fixar um sentido sobre os demais, conforme Mariani (1993), ou seja, estabelecer um sentido homogêneo para os processos. 
Nesse sentido, Orlandi e Guimarães (2001, p. 22-24) apontam quatro momentos essenciais ao longo da história do Brasil (a partir da colonização) para a instituição do português como língua nacional do País.

O primeiro momento diz respeito ao período do início da colonização até a expulsão dos holandeses (1654), quando há uma espécie de "língua geral", pela qual se comunicavam índios e portugueses. Por sua vez, a língua portuguesa é falada por "um pequeno número de pessoas, notadamente por letrados, grandes proprietários de terras (os Senhores de Engenho) e uma pequena minoria de funcionários" (ORLANDI; GUIMARÃES, 2001, p. 22). Por ocasião da disputa colonial com os holandeses, o português é "ensinado nas escolas católicas e empregado nos documentos oficiais".

O segundo momento segue até a chegada da família real, em 1808, período em que aumenta o número de portugueses no Brasil, mas também cresce o número de africanos, em decorrência do crescimento da escravidão no País. Com este movimento, "a relação entre o português, língua da colônia, e as diferentes línguas faladas no Brasil é então modificada" (idem, p. 22), sendo difícil estabelecer uma distinção das línguas aqui faladas.

Nesse segundo momento da divisão proposta por Orlandi e Guimarães, cabe também ressaltarmos a ação de Marquês de Pombal, ainda no século XVIII, que tornou o ensino de português obrigatório nas escolas jesuítas, proibindo o ensino das línguas indígenas, sendo este um primeiro passo na direção da unificação da língua portuguesa no Brasil. Com o ensino de português passando a ser obrigatório nas escolas, ele é "a uma só vez a língua do Estado e a língua dominante" (ORLANDI; GUIMARÃES, 2001, p. 23).

O terceiro momento inicia com a chegada da família real ao Brasil, o que movimenta 15.000 portugueses para a nova Coroa, modificando "as relações entre as línguas faladas no Rio de Janeiro". Além do impacto desse movimento, destacase também a criação da Biblioteca Nacional e da imprensa no País por D. João VI (ORLANDI; GUIMARÃES, 2001, p. 23).

Ainda no entender de Orlandi e Guimarães (2001), o terceiro momento se encerra pouco tempo após a independência brasileira, dando início ao quarto momento, quando surgem as discussões sobre a denominação da língua aqui falada (língua brasileira x língua portuguesa), o que podemos considerar como o "pontapé inicial" da construção de uma memória sobre a "língua nacional".

Assim, no quarto momento, passa-se a refletir sobre a unidade linguística e, justamente por isso, busca-se uma instrumentalização da língua. Nesse sentido, para Costa (2013, p. 105-106):

A gramatização do português-brasileiro, então, pode ser entendida como o início de um momento que vem sendo processado desde antes da nossa independência, em que surgem novos sentidos e em que se configura uma nova subjetividade para o povo brasileiro; não se trata mais simplesmente de um povo colonizado pela metrópole portuguesa, mas de cidadãos de uma nação independente e que, por isso, têm novas obrigações e deveres.

A partir do século XIX, há uma proliferação de gramáticas brasileiras e, com elas, a construção de um imaginário de língua normatizada, ou, segundo Petri, "toda 
regulada na e pela gramática normativa" (2011, p. 26). Ou seja, surge o imaginário de uma língua que seria passível de ser totalmente descrita e apreendida pelos brasileiros a partir do conhecimento da gramática. Nesse sentido, são relevantes as noções de língua imaginária e língua fluida propostas por Orlandi e Souza (1988).

A língua imaginária, conforme as autoras (1988), é aquela sistematizada pelos estudiosos da linguagem, que, a partir de artefatos e de "objetos-ficção", torna-se a língua da norma, instrumento de coerção a partir do domínio de seus saberes. A língua fluida, por sua vez, não é passível de normatização, é a língua que não cabe em um conjunto de normas. "É a língua do mundo, sem regras que a aprisionem, língua no acontecimento do significar na relação de homens com homens, sujeitos e sujeitos" (ORLANDI, 2002, p. 13).

Nesse sentido, a "língua nacional" corresponderia à definição de língua imaginária, encaixotada como um sistema, mas sempre relacionada à língua fluida, que não é passível de controle e, por isso mesmo, não deixa de circular.

A fim de aprofundar um pouco mais a noção de gramatização, apoiamo-nos em Surdi e Petri (2010), as quais afirmam que o termo gramática, inicialmente, remete a um conjunto de regras individuais, sendo, no Brasil, uma herança da língua de Portugal e resultado desse longo processo de gramatização da Língua Portuguesa em nosso País. Ela é entendida como um instrumento que contém o saber sobre a língua, um "manual de bem falar e bem escrever" (SURDI; PETRI, 2010 , p. 03). A gramática normativa prescreve as normas de uma língua que se quer homogênea, ou seja, única e padronizada, sendo uma força conservadora na linguagem.

Nesse sentido, Auroux (1992, p. 65) traz o processo de gramatização como uma revolução tecnológica, semelhante ao surgimento da escrita, que se dá a partir do Renascimento na Europa e, posteriormente, em todo o mundo ocidental. Este processo "conduz a descrever e a instrumentar uma língua na base de duas tecnologias, que são ainda hoje os pilares de nosso saber metalinguístico: a gramática e o dicionário". Assim, a gramática e o dicionário seriam não só descrição da linguagem natural, eles são percebidos por Auroux como instrumentos linguísticos.

Com o intuito de ensinar "o bem falar e o bem escrever" é que as escolas tomam a gramática como instrumento de ensino da língua, numa perspectiva pedagógica totalmente vinculada à gramatização, à normatividade e, consequentemente, ao par erro/acerto.

Para Auroux (1992, p. 36), "a gramática se torna simultaneamente uma técnica pedagógica de aprendizagem das línguas e um meio de descrevê-las". É por esse imaginário do saber escolar, ancorado em uma memória de língua instrumentalizada, que se acredita ser possível "domar" a língua pelo domínio de suas regras, conhecimento que só alguns detêm.

Podemos também afirmar que a língua também serve como instrumento de segregação. Segundo Dorneles, Cazarin e Schons (2011, p. 38), “O imaginário constituído acerca da língua faz a separação dos corpos no espaço social, dando voz a alguns e tirando-a de outros". Daí afirmar que a língua é instrumento de poder e dominação, uma vez que aqueles que não possuem domínio de seu "conjunto de 
normas de bem falar e bem escrever" não são capazes de vivenciar determinadas situações, sendo, portanto, excluídos.

Tal constatação se mostra extremamente relevante para nossas análises, motivo pelo qual trataremos, na seção a seguir, que arquivo de saberes é esse que o revisor deve possuir.

\subsection{Arquivo das "coisas-a-saber"}

O arquivo, na perspectiva discursiva, é definido por Pêcheux (1997, p. 57) como um "campo de documentos pertinentes e disponíveis sobre uma questão", sobre o qual se produz um gesto de leitura e a partir do qual é acionada uma memória.

Em seu texto Ler o arquivo hoje, Pêcheux (1997, p. 57) descreve a posição de enfrentamento em que se colocam duas culturas de tratamento de arquivos na França: a literária, que faria uma leitura solitária e implícita; e a científica, que utilizaria os textos como dados, levando a um gesto de leitura duro, burocrático e quase matemático. Sua proposta, no entanto, é que a leitura de arquivo seja um gesto de reconhecer as "evidências", "mergulhando a leitura literal numa leitura interpretativa - que já é uma escritura", transformando o trabalho de ler o arquivo em um espaço polêmico das maneiras de ler.

Para ele, a leitura científica dos arquivos sempre interessou aos aparelhos de poder, uma vez que é dessa forma que se geram as memórias coletivas da sociedade. Assim, somente os "autorizados" podem falar sobre essas memórias, ou seja, produzir sobre elas gestos de interpretação. Aos outros, somente é autorizado repetir, classificar, transcrever, uma vez que, nesses gestos de leitura, há um apagamento do sujeito.

É dessa maneira que tais métodos de tratamento em massa, isto é, o gesto de leitura repetido coletivamente, como se o sentido fosse único e incontestável, servem a fins estatais ou comerciais, os quais "supunha torná-los facilmente comunicáveis, transmissíveis e reproduzíveis". Pêcheux denomina esta separação como divisão social do trabalho de leitura. Divisão semelhante identificamos em nosso objeto: alguns possuem o direito de produzir leituras originais, enquanto a outros somente cabe a tarefa "subalterna" de preparar e de sustentar as interpretações já realizadas.

Assim, nos dizeres aqui analisados, percebemos a tentativa de acesso a um arquivo, no qual constaria o conjunto de saberes que um revisor de publicidade deve possuir. A esse arquivo, chamaremos arquivo de saberes do revisor, ao qual os publicitários têm acesso parcial por meio do que Orlandi (2010b) denominou memória institucional. Diferentemente da memória discursiva, esta é uma memória de arquivo, que fica disponível para ser acessada. Orlandi (2010b) afirma que é por meio dessa memória que o sujeito pode acessar saberes institucionalizados.

Observando as SDs 1 e 2 a seguir, percebemos um processo parafrástico que diz respeito àquilo que o revisor deve saber: 
SD1 $[\mathbf{A T T}]^{3}-$ O redator tem que saber escrever.... porém a expertise dele é tentar escrever da melhor forma para vender aquele produto ou divulgar aquele produto.... O revisor é totalmente o português as regras ortografia pelo menos ao meu ver... então eu acho que são duas coisas diferentes... os dois tem que saber português... mas um tem que saber escrever e de que forma vai expressar aquilo e o outro tem que saber se aquela forma que ele colocou tá correta né.

SD2 [RD] - Que entenda o português/ a língua portuguesa/ mais até do que eu.... Detalhes de coisas que eu não sei/ eu uso o revisor bastante pra dúvidas que eu tenho... Eu tenho o conhecimento da língua portuguesa normal como uma pessoa que lê que tem contato... mas as regras da língua portuguesa/ tem muita regrinha xarope isso não sei... Aí eu acho legal pra dizer como se escreve/ fica melhor assim/ ou pergunto se tá errado/ até onde eu posso ir sem tá deturpando ela.

A partir disso, identificamos que a publicidade percebe o revisor de textos como um grande aliado para seu objetivo comercial: é o revisor quem pode tornar o texto mais "facilmente comunicável". É o que se espera dele, afinal, acredita-se que ele possua o domínio da ciência da linguagem, das regras que, na visão dos publicitários, são evidentes para o revisor e que seriam instrumentos aplicáveis capazes de deixar um texto mais legível.

O processo parafrástico é percebido, nas SDs 1 e 2, especialmente entre os significantes português/língua portuguesa e as sentenças regras/ortografia/se aquela forma tá correta. Nessas sequências, observamos a língua sendo tomada como equivalente às regras, ao saber gramatical e à correção de textos. Ambas SDs apontam para um mesmo efeito de sentido: o revisor deve ser um sujeito do saber gramatical, o que nos leva a perceber os sujeitos se identificando plenamente com os saberes de uma posição-sujeito em que o revisor é entendido como um corretor.

Percebe-se, ainda, o estabelecimento de comparações entre os saberes do revisor com os saberes de outros sujeitos da agência. Nas SDs 1 e 2, os sujeitos comparam os saberes do revisor com os do redator: redator sabe escrever, sabe português, mas sabe como uma pessoa normal, que lê, enquanto o revisor sabe regras, normas, sabe como não deturpar a língua, sabe dizer como se escreve mas, nos perguntamos, ao mesmo tempo, não saberia ele mesmo escrever? Pelo que percebemos pelo funcionamento dessas Sds, saber escrever não é um dos saberes enumeráveis do revisor.

O significante regras, que é recorrente nos dizeres sobre o revisor da publicidade, aponta para o que é correto, para o que leva a evitar o erro. Assim, quem detém o conhecimento das regras é quem possui o poder de deixar o texto/ trabalho correto. Nas SDs acima, vemos que a existência de regras é evidente, mas as regras em si são da ordem da opacidade para os publicitários. Uma vez que não são evidentes para todos, elas são transformadas em regrinha xarope, diminuindo uma importância que eventualmente as coisas a saber do revisor

\footnotetext{
${ }^{3}$ As siglas a seguir correspondem aos lugares sociais ocupados pelos sujeitos dentro da agência publicitária: AT - Atendimento; RD - Redator; RV - Revisor.
} 
poderiam ter. Assim, as regras funcionam como um pré-construído das coisas a saber que concernem ao revisor e retornam, no discurso desses sujeitos, com uma maior ou menor importância, dependendo do lugar discursivo que ocupa aquele que fala sobre elas.

Nesta outra sequência da SD2: Detalhes de coisas que eu não sei/ eu uso o revisor bastante pra dúvidas que eu tenho..., percebemos que o revisor é trazido como um instrumento gramatical de apoio, passível de uso e muito mais acessível do que recorrer à gramática ou ao dicionário, porque basta perguntar que o revisor pode dizer como se escreve. Dessa maneira, entendemos que o revisor está sendo discursivizado como um instrumento da língua que faz parte, juntamente com gramáticas e dicionários, do suporte instrumental que o publicitário precisa para bem escrever.

Observemos, ainda, a SD3, que responde à questão o que o revisor podel deve fazer?:

SD 3 - Eu acho que tudo o que é escrito errado ele deve fazer, o que não está de acordo.

Já havíamos observado, nas SDs anteriores, a repetibilidade do significante erro. Nesta SD, percebemos o erro relacionado a uma falha, ao desacordo com um padrão. Pela leitura desta SD em contraste com as anteriores, entendemos que os significantes relacionados ao erro, embora apareçam como algo evidente, resultam de uma construção histórica, que intervêm como pré-construídos sobre a língua. Ou seja, parece evidente que algo que esteja fora do padrão do conjunto de regras da língua portuguesa seja considerado um erro em um texto e, sendo o revisor aquele que possui o domínio dessas regras, espera-se dele que cace esses erros.

Ainda em relação à SD3, ressaltamos o que afirma Petri (2011, p. 25): “faz parte do nosso imaginário social a convenção de que aquele que ensina a língua deve saber 'tudo', deve dominar a tal 'língua culta', conhecer muito de gramática e, preferencialmente, ser um 'dicionário ambulante"”. Deslocando esse imaginário que funciona em relação ao professor de línguas, conforme mencionado por Petri, para o profissional de Letras, e especificamente para o revisor, percebemos que a este é imputado que detenha o conhecimento do todo da língua, o que, tomando língua como gramática, lhe daria o domínio desta, ou a possibilidade de deixar um texto de acordo (com a gramática? Com o que deseja o cliente? Com o que quer o redator?).

Assim, os saberes do revisor seriam colocados em prática quando este garantisse uma perfeita comunicação, como podemos observar na SD a seguir, em que o revisor responde à questão: "Em que medida o trabalho do revisor interfere no resultado final do processo?":

SD4 [RV] - Eu acho que a revisão, assim, como eu te disse, é o processo onde a gente/ o momento onde a gente acalma né... tem a tranquilidade de ver se tá tudo correto... Eu tento sempre ter a visão do primeiro leitor/ digamos assim/ se aquela peça tá bem clara/ se aquela peça/ enfim... tá transparente pra mim /porque às 
vezes assim o pessoal que tá aqui dentro na correria, ou o cliente tá tão habituado com aquela campanha, com aquela linguagem, que às vezes um elemento que tá numa peça, não tá presente em outra, e naquela outra não fica tão claro o que eles quiseram dizer... o que eles querem comunicar... Então eu tento ter o olhar o mais neutro possível. Nunca pensando assim se foi o Redator X que escreveu ou se foi o assistente de redação que escreveu. Não interessa isso, tu tem que ver se o texto tá claro, se tá comunicando bem, e é isso...

Nesta SD, enunciada por um sujeito-revisor, percebemos que os significantes claro, clareza, comunicar bem, transparente funcionam como paráfrases de correto, uma vez que o texto só estaria correto se não possuísse erros que prejudicassem sua clareza, sua transparência para comunicar. Isso está ligado ao que afirma Mittmann (2010, p. 11) a respeito de uma perspectiva tradicional sobre língua, quando diz que parece haver 'uma espécie de 'cola' entre a língua e pensamento: quando se aprende uma língua correta é possível apresentar com clareza o pensamento". Identificamos aqui o funcionamento dos esquecimentos do sujeito que, ao se imaginar responsável pela transparência do sentido e pela garantia da comunicação, esquece que os sentidos não estão colados às palavras e expressões.

Nesse sentido, o revisor se acredita detentor dos saberes da língua, saberes que o habilitam a verificar se o texto está claro, ou se possui erros que "tirem" dele a transparência. Ainda com Mittmann (2010, p. 11), podemos afirmar que "permanece o imaginário de língua como instrumento de comunicação (ou convencimento) e de gramática como descrição e prescrição a fim de capacitar os sujeitos à melhor comunicação e ao mais efetivo convencimento". Em nossas análises, percebemos que, enquanto o redator dominaria a parte da língua relativa ao convencimento, à persuasão, o revisor garantiria que a comunicação se efetivasse, tornando o texto claro.

Ainda, percebemos essa clareza como uma tentativa de fechamento dos sentidos, o que, para Gallo (2008), é entendido como legitimação, a qual está ligada ao esquecimento $\mathrm{n}^{\mathrm{o}} 2$ e é caracterizada por ser o processo que legitima, faz parecer único, um sentido determinado de um determinado enunciado.

Em outras palavras, o sujeito busca o efeito de fechamento dos sentidos, na tentativa de que o discurso não seja entendido de nenhuma outra forma pelo leitor. Ele busca dar transparência ao texto, esquecendo-se que a linguagem não é transparente. Ou seja, o sujeito acredita-se o único cuja capacidade de acalmar o processo, de ter um olhar neutro e não dar espaço à falha é legítima.

Vejamos uma das sequências discursivas, na qual temos resposta à pergunta "Qual a importância do trabalho do revisor?":

SD5 [AT] - Super importante, é uma pessoa que está por dentro da língua portuguesa, que é uma língua que não lidamos todos os dias, e muitos trabalhos temos que saber a forma de falar, se está correto, se possui licença poética ou não. Às vezes um erro de português pode levar a marca ou a empresa a outro patamar, 
que pode prejudicar muito. Por estar no Brasil, o mínimo que tem que saber é falar a língua daqui.

Nessa SD, é possível observar, inicialmente, a circulação de uma memória que remete a dois pré-construídos: 1) o revisor como o detentor de um conhecimento específico sobre a língua; 2) a língua é equivalente à gramática normativa, à qual nem todos têm acesso.

Ressoa uma memória do processo de gramatização, de que falam Orlandi e Guimarães (2001), o que é possível observar a partir da descrição do revisor como alguém que está por dentro da língua portuguesa. O sentido de língua portuguesa, aqui, equivale ao conceito de língua imaginária, aquela sistematizada a partir de um saber gramatical, que seria um conjunto de regras gramaticais das quais o revisor teria conhecimento. Isso é perceptível quando o sujeito publicitário diz que o revisor está por dentro de algo que ele e os outros publicitários não lidam todos os dias, ou seja, língua portuguesa aqui não aparece com o sentido de língua fluida, uma vez que essa seria a língua de todos os dias.

Essa sequência também nos dá pistas de uma memória de língua que, por ter sido forjada como nacional, constantemente parece estrangeira. No trecho " $O$ mínimo que tem que saber é falar a língua daqui", a SD apresenta um saber que parece ser necessário somente ao revisor. Saber falar a língua daqui não é uma especificidade do revisor, mas de qualquer sujeito falante de língua portuguesa do Brasil.

Nesse sentido, conforme Costa (2013, p. 118):

O gramático hierarquiza a língua conforme o grau de escolarização dos falantes, e coloca a "língua geral" em um patamar que somente tem acesso aqueles que têm um maior grau de escolarização e de cultura. Dessa forma, manifesta-se a força impositiva e excludente da gramática, que elege como padrão a modalidade dos mais escolarizados para excluir socialmente os menos aparelhados linguisticamente. A sobreposição da "língua geral" em relação à "língua regional" aponta para o forte controle da escola e da gramática para impor um imaginário de língua homogênea sobre as formas não padronizadas e, assim, legitimar o discurso de que o brasileiro não sabe falar a própria língua. (Grifos nossos).

Dessa forma, vemos funcionar, nessa SD, um pré-construído sobre a língua portuguesa tomada como uma língua estrangeira, de difícil apreensão, pois se considera a língua como equivalente ao seu conjunto de regras, ao saber gramatical que não é acessível a qualquer um, e que, na agência, somente o revisor possuiria.

A língua daqui, que aparece na SD acima, não é algo evidente. Isso se explica pelo que traz Orlandi (2002, p. 23), pois sempre estaremos, como brasileiros, num "ponto de disjunção" entre a língua portuguesa de Portugal e a do Brasil. Há um efeito de homogeneização sobre elas, o que leva o sujeito a uma sensação de não saber a língua que, resultado do processo histórico de colonização, como vimos anteriormente, não é uma língua daqui, mas que "significa em uma filiação de memória heterogênea".

Não podemos esquecer que sujeito e língua são inseparáveis, então, o sujeito está sempre "dentro" da sua língua materna, porque fora dela não existe sujeito, nem sentido. Quando aprende uma língua estrangeira, ele se posiciona na 
exterioridade e tateia aqueles sons na busca por sentidos. Se os publicitários se acreditam "fora da língua", então, essa língua não seria materna. Assim, somente aqueles que possuem o saber gramatical é que saberiam a língua daqui, e estariam por dentro dela, sendo capazes de lidar com ela todos os dias. Nesse sentido, o revisor "fala" uma língua estrangeira, sendo essa uma competência que se espera dele e, nisso, reside sua importância no processo.

Nesse sentido, o publicitário, como vimos na SD5, percebe que não possui os mesmos saberes que o revisor, sendo este último apto a lidar com a língua. Assim, apesar do revisor possuir o "domínio do bem falar e bem escrever", a ele é atribuído muito mais a correção gramatical e o saber sobre o conjunto de regras da língua, a fim de aplicá-las para evitar um erro, do que o bem escrever. Dessa forma, ao redator se atribui o poder de escrever e de aprovar ou não as correções/ sugestões realizadas pelo revisor. Nessa relação, a língua do revisor é a língua das regras, burocrática, enquanto a do publicitário é uma língua leve, da licença poética, da sacada publicitária, ou seja, de um saber criativo muito diferente do saber técnico atribuído ao revisor.

Já para o sujeito que ocupa o lugar discursivo de atendimento, como na $\mathrm{SD} 5$, o revisor é quem garante que o trabalho saia sem erros, é ao revisor que o atendimento recorre para saber a forma de falar, se está correto. A partir dessa posição, percebemos que o atendimento não representa somente a voz do cliente dentro da agência, mas representa sempre a voz do outro, uma voz que nunca é sua. Assim, a língua permanece sendo instrumento de poder e dominação, no entanto, na relação entre atendimento e revisor, parece que há uma relação de dominância deste último sobre o atendimento, que é garantida pelo saber.

Nosso corpus aponta, portanto, para a divisão social da leitura de que falava Pêcheux, já que os sujeitos publicitários são aqueles que possuem o "poder" ou o "direito" de entender o que o cliente deseja comunicar, escrevendo e criando os anúncios. Caberia, então, ao revisor a "tarefa subalterna" de realizar o tratamento dos textos, de forma a torná-los mais compreensíveis e evidentes ao público, dirimindo ambiguidades, apagando qualquer falha que venha a acontecer, embora não lhe seja dado o direito de interpretar - ou de alterar o texto fora dos limites a ele imposto.

\subsection{A língua da criação publicitária}

Ao apontar para uma diferença entre saber sobre a língua e saber a língua, no sentido de saber bem falar e bem escrever, Orlandi (2002) nos leva a perceber que é nessa diferença que reside a interdição do revisor em escrever: ele é visto como aquele que sabe sobre a língua, sobre suas regras e modos de "usar". Mas isso não está ligado ao saber bem escrever ou bem falar, ainda que ele seja consultado para isso, como vimos anteriormente.

Observemos as SDs a seguir, nas quais, ao falar sobre o trabalho do revisor, sobre o que este pode/não pode/ deve/não deve fazer, os sujeitos acabam trazendo as concepções de língua que percebem na publicidade: 
SD6 [RD] - Acho que pode alterar desde que não comprometa o conteúdo da escrita. Se é pra melhorar a forma da escrita, ou corrigir coisas eu não me importo, desde que não mude o conteúdo. E depende também porque têm muitos revisores que vão pelo português literal, isso a propaganda, ela usa o falar. Então deixa a frase dura. Eu tô aberto a opiniões, agora se eu achar que é ruim, que a frase vai ficar dura, mesmo que seja o mais correto colocar desse jeito, se não tá errado, deixa assim.

SD7 [RD] - Geralmente os revisores de agência têm essa visão um pouco mais livre não do português completamente, não é que eles não corrijam o português, mas eles sabem que propaganda não é uma coisa assim tão literal.. [...] texto de propaganda é uma coisa que tu precisa aproximar ao máximo das pessoas, não é um português cultíssimo que tu vai encontrar, às vezes tu te permite liberdades, até um certo ponto, que geralmente o revisor de agência tá por dentro disso, e já tá com esse olho mais treinado de ok, isso não precisa ser exatamente perfeito, mas o texto tá correto, tá sendo entendido, qual é a melhor maneira então...

SD8 [AT] - Eu acho que é total. A gente tem aquela coisa do livre-arbítrio pra fazer um texto diferenciado, com uma linguagem própria, com uma sacada publicitária como a gente diz, né? Mas eu acho que é fundamental o revisor pra que a gente respeite o mínimo da coerência, da norma da língua portuguesa. Pode ser um texto diferente, uma pegada mais moderna, mais atual, de acordo com cada público. Mas eu acho fundamental a gente ter um revisor de textos pra que aquilo esteja adequado e de bom tom aos ouvidos do leitor, de quem tá recebendo aquela mensagem. Pra que a gente esteja comunicando de maneira correta.

Pela observação dessas SDs, percebemos um retorno à língua imaginária proposta por Orlandi, da qual falamos anteriormente. Isso se dá por meio das expressões português literal e deixar a frase dura, as quais remetem para o revisor como sujeito que domina determinados saberes gramaticais e, portanto, deixaria o texto duro. Ao mesmo tempo, a publicidade apresenta-se a partir de um imaginário de língua fluida: a linguagem da "sacada", das figuras de linguagem, da criatividade, sendo uma língua que permite liberdades e que se opõe aos conhecimentos de língua do revisor, que seriam da ordem da língua imaginária.

Diferentemente funciona a SD7, na qual o sujeito aponta que o revisor possuiria o conhecimento não só das normas, mas também de uma linguagem mais livre como a da publicidade. Porém, permanece o imaginário do revisor como aquele capaz de deixar o texto comunicável, por meio da correção, como vimos anteriormente.

Na SD8, percebemos o imaginário de um sistema de comunicação perfeito, composto por locutor - mensagem - receptor, o qual seria garantido por meio do revisor. Percebemos, nessa SD, que a publicidade faz a língua parecer "instrumento de comunicação ideologicamente neutro" (ORLANDI, 1998, p. 12). A AD, no entanto, percebe a língua como sujeita a falhas, a equívocos, a mal-entendidos. Ela não é, para a $\mathrm{AD}$, um instrumento passível de uso, mas sim o "lugar material de realização dos processos discursivos, onde se manifestam os sentidos" 
(LEANDRO FERREIRA, 2003, p. 196), o que nos leva a olhar diferentemente para os efeitos de sentido dos dizeres sobre o revisor.

Se, tal como fala Scherer (2007, p. 350), no discurso sobre a língua a contradição é o próprio modo de significação, que língua seria essa, que ao mesmo tempo que se quer livre, precisa de correção para se tornar comunicável? Impõe-se aí uma contradição: por um lado, a língua da publicidade deve ser fluida, permitir liberdades, aproximar do público, usar o falar, ou a linguagem coloquial; por outro, os anúncios são remetidos ao revisor de textos, mesmo que se acredite que ele pode deixar o texto duro, mesmo que ele corrija o que está errado para deixar mais comunicável.

Podemos afirmar, então, que essas SDs apontam para a identificação do sujeito com uma posição-sujeito na qual se entende que revisão é correção. A partir da identificação com essa posição-sujeito, há um entendimento de língua enquanto gramática, como se esta se confundisse com o conjunto de normas de uma língua, ou seja, uma língua imaginária.

Para Gadet e Pêcheux (2010, p. 24), a língua da publicidade seria uma língua de vento, a qual se "enrosca" com a língua de madeira, que seria a classificação da língua relativa ao direito e à política. Essa última é percebida como uma língua à qual não se tem acesso, uma língua dura, que se presta a uma "maneira política de denegar a política”. Já a língua da publicidade e da propaganda serve ao capitalismo. Assim, uma vez que se presta à persuasão, ela é rápida e leve como vento, a fim de ser facilmente compreendida.

Pensando no discurso político na atualidade, a partir das metáforas de Lula, Daltoé (2011) concebe a noção de língua de barro, uma língua que, apesar de política, não manteria a dureza da língua de madeira, ou da língua de ferro, pensadas por Gadet e Pêcheux (2010). A língua de barro seria, segundo Daltoé (2011, p. 193), uma língua maleável, uma vez que o material permitiria “transformá-la, revirá-la, torcê-la e distorcê-la", mas, ao mesmo tempo, torná-la tensa após a aplicação de uma força, deixando marcas de um novo modo de enunciar dentro dela.

Inspirados na proposta de Daltoé e operando o deslocamento necessário para o espaço da publicidade - distinguindo-o do campo político abordado pela autora - poderíamos dizer que a língua da criação publicitária seria uma língua de gesso. Pensando nessa imagem, inicialmente, a percebemos como pó: a língua "vem" do cliente (anunciante) por meio de uma ideia sem forma, a ser moldada pelos publicitários com base em condições como verba e público. Na agência, é "acrescida" a criatividade, que possibilita que ela seja moldável, tendo os sentidos trabalhados por diversas mãos, de forma solta, leve e aberta, maleável como gesso molhado. Mas, ao final do processo, assim como o gesso endurece, a língua da criação publicitária passa por um processo de revisão que se quer normativo, que trate a língua como um conjunto de regras, transformando-a em uma língua dura como o gesso seco, ainda que conserve a possibilidade de ser novamente maleável. Assim, somente quando o texto publicitário vai para circulação é que a língua se transformaria na língua de vento da publicidade, já assim definida por Pêcheux. 


\section{CONSIDERAÇÕES FINAIS}

A partir da análise de algumas SDs, tomadas como exemplares dos dizeres sobre o revisor de textos da publicidade, foi possível observar a discursivização do revisor de textos e a circulação de um certo imaginário de língua.

Se o revisor é tomado como um detentor do saber gramatical, alguém a quem se consulta para saber bem escrever, é possível afirmar que ocorre uma instrumentalização do sujeito, uma vez que ele é discursivizado como um instrumento usado para evitar o erro, para proporcionar clareza aos textos publicitários a partir do conjunto de saberes - passíveis de serem aplicados - que possui.

Ele é visto, a partir da identificação com uma posição-sujeito em que "revisão é correção", como um corretor de erros, um apoio técnico, alguém que está fora do processo de criação. Tal visão o coloca lado a lado com outros instrumentos de gramatização, tal como a gramática e o dicionário.

Além disso, circula, nesse espaço de dizeres, um imaginário de língua colada à gramática, passível de domínio - enquanto língua do revisor -, mas ligada à criatividade enquanto língua do publicitário. Isso contribui para nossa proposta de que a língua da criação publicitária seria uma língua de gesso, a qual passa de maleável - pelo publicitário - para um processo de "endurecimento" quando "nas mãos" do revisor.

\section{REFERENCIAS}

AIUB, Giovani Forgiarini. Arquivo em Análise do Discurso: uma breve discussão sobre a trajetória teórico- metodológica do analista. Leitura, Maceió, n. 50, p. 61-82, jul./dez. 2012.

AUROUX, Sylvain. A Revolução Tecnológica da Gramatização. Campinas: Editora da Unicamp, 1992.

COURTINE, Jean-Jacques. Análise do discurso político: o discurso comunista endereçado aos cristãos. São Carlos: Ed. UFSCar, 2009.

COSTA, Thaís de Araujo da. Significando e garantindo a língua nacional: o processo de historicização da língua portuguesa do brasil e a implementação da nomenclatura gramatical brasileira. RevLet - Revista Virtual de Letras, v. 05, n. 02, ago./dez. 2013.

DALTOÉ, Andréia da Silva. As metáforas de Lula: a deriva dos sentidos na língua política. $220 \mathrm{f}$. Tese (Doutorado em Estudos da Linguagem) - PPG Letras - Universidade Federal do Rio Grande do Sul, Porto Alegre, 2011.

DORNELES, Elizabeth Fontoura; CAZARIN, Ercília; SCHONS, Carme Regina. Discurso sobre a língua e a constituição da língua da escola. In: SCHONS, Carme Regina; CAZARIN, Ercília Ana. (Orgs.). Língua, escola e mídia en(tre)laçando teorias, conceitos e metodologias. Passo Fundo: Ed. Universidade de Passo Fundo, 2011, p. 34-47. 
GADET, Françoise; PÊCHEUX, Michel. A língua inatingível. O discurso na história da Linguística. 2. ed. Tradução Bethânia Mariani e Maria Elizabeth Chaves de Mello. Campinas: Editora RG, 2010.

GALLO, Solange Leda Maria. Como o texto se produz: uma perspectiva discursiva. Blumenau: Nova Letra, 2008.

HANSEN, Fábio. A noção de pré-construído e seus desdobramentos no processo criativo do discurso publicitário. Organon, UFRGS, v. 24, n. 48, 2010. Disponível em: <seer.ufrgs.br/organon/ article/download/28644/17323 >

LEANDRO FERREIRA, Maria Cristina. O caráter singular da língua no Discurso. Organon - Revista do Instituto de Letras da UFRGS, v. 17, n. 35, p. 86-99, Porto Alegre, 2003.

LEANDRO FERREIRA, Maria Cristina. Memória discursiva em funcionamento. In: ROMÃO, Lucília Maria Souza; CORREA, Fernanda Silveira. Conceitos discursivos em rede. São Carlos: Pedro \& João Editores, 2012.

MARIANI, Bethânia. Os primórdios da Imprensa no Brasil (ou: de como o discurso jornalístico constrói memória). In: ORLANDI, Eni Puccinelli (Org.). Discurso Fundador - a formação do País e a construção da identidade nacional. Campinas: Pontes, 1993, v. 01, p. 32-43.

MITTMANN, SOLANGE. Língua, gramática e normatização em discursos de arquivo. In: UFRGS/ COPERSE. Reflexões linguísticas e redação de vestibular. Porto Alegre: Ed. da UFRGS, 2010.

ORLANDI, Eni. O próprio da Análise do Discurso. Escritos, Discurso e Política, n. 3, Labeurb, Campinas, 1998.

ORLANDI, Eni. Língua e conhecimento linguístico. Para uma História das Idéias no Brasil. São Paulo: Cortez, 2002.

ORLANDI, Eni. Análise de Discurso. In: ; LAGAZZI-RODRIGUES, Suzy (Orgs.). Introdução às Ciências da Linguagem: discurso e textualidade. 2. ed. Campinas: Pontes, 2010a.

ORLANDI, Eni. A contrapelo: incursão teórica na tecnologia - discurso eletrônico, escola, cidade. Revista Rua, Campinas, n. 16, v. 2, nov. 2010 b.

ORLANDI, Eni.; GUIMARÃES, Eduardo. Formação de um espaço de produção linguística: a Gramática no Brasil. In: ORLANDI, Eni (Org.). História das Ideias Linguísticas: construção do saber metalinguístico e constituição da Língua Nacional. Campinas: Pontes; Cáceres: Unemat, 2001.

ORLANDI, Eni; SOUZA, Tania de. A língua imaginária e a língua fluida: dois métodos de trabalho com a linguagem. In: ORLANDI, Eni (Org.). Política linguística na América Latina. Campinas: Pontes, 1988.

PÊCHEUX, Michel. Ler o arquivo hoje. In: ORLANDI, Eni (Org.). Gestos de Leitura: da história no discurso. Campinas: Unicamp, 1997.

PÊCHEUX, Michel. Papel da memória. In: ACHARD, Pierre et al. Papel da memória. Campinas: Pontes, 1999. 
PÊCHEUX, Michel. Semântica \& Discurso: uma crítica à afirmação do óbvio. Campinas: Unicamp, 2009.

PETRI, Verli. Contribuições da análise de discurso para o ensino de língua: em busca da desconstrução da unidade imaginária. In: SCHONS, Carme Regina; CAZARIN, Ercília Ana. Língua, escola e mídia: en(tre)laçando teorias, conceitos e metodologias. Passo Fundo: Editora UPF, 2011.

SARAMAGO, José. História do Cerco de Lisboa. Editorial Caminho, 1989.

SCHERER, Amanda Eloina. A constituição do eu e do outro pela interpelação da língua pela língua na história do sujeito. In: LEANDRO FERREIRA; INDURSKY, Freda. Análise do Discurso no Brasil: mapeando conceitos, confrontando limites. São Carlos: Claraluz, 2007.

SURDI, Marcia; PETRI, Verli. Língua: o "diferente" no interior do mesmo na gramática. Revista de Letras, v. 12, n. 12, 2010. Disponível em: <http://www.dacex.ct.utfpr.edu.br/12_LÍNGUA. htm>. Acesso em: 26 dez. 2015. 